\title{
Recruitment and functionality traits as bioindicators of ecological restoration success in the Lurg Hills district, Victoria, Australia
}

\author{
Kristin Monie, Singarayer Florentine ${ }^{*}$ and Grant Palmer
}

\begin{abstract}
Introduction: The Regent Honeyeater Project commenced ecological restoration in the Lurg district in 1994, with an aim to restore habitats for the critically endangered Regent Honeyeater Anthochaera phrygia and a range of other threatened and declining species. Within this context, our study aimed to explore whether plant reproduction can be an effective measure of ecological restoration success.

Methods: Evaluation involved comparing attributes at unrestored, restored and remnant sites to establish whether sites displayed evidence of a clear restoration trajectory. Five age classes (unrestored, 4-6 years old, 8-10 years old, 12-14 years old and remnant areas) and two landforms (upper hills and lower hills) were considered. The diversity of woody plant species - which have easily recognisable reproductive material and which all recruit seedlingsprovides easily measured parameters that have the potential to allow the determination of early establishment success and long-term ecological development of restored ecosystems.
\end{abstract}

Results: Restoration plantings developed in a hybrid state towards a benchmark in the lower hills; seedling species composition differed significantly among age classes, increasing in similarity with time since restoration, with some divergence from the target pathway. Composition of functional groups with reproductive outputs was also significantly different among age classes; however, a restoration trajectory was only evident in the upper hills where sites converged towards the target goal.

Conclusions: Divergence or deviation from the restoration trajectory was not deemed to be a restoration failure, as the variety of functional groups with fruits and diversity of seedlings recruiting indicated a potential increase in resilience in the future due to greater variability across the landscape. Plant recruitment was effective in detecting development trends towards a restoration target in this study and therefore may be a useful measure that contributes to determining ecological restoration success.

Keywords: Restoration; Assessment; Ecological development; Trajectory; Monitoring

\section{Introduction}

Monitoring and evaluation of restoration activities are critical steps toward developing and improving upon ecological restoration practices (Lindenmayer and Likens 2010; Lindenmayer et al. 2012). However, despite vastly greater investments in on-ground works (Wilkins et al. 2003), the proportionally little monitoring of revegetated sites that has been conducted has sometimes been

\footnotetext{
* Correspondence: s.florentine@ballarat.edu.au

Centre for Environmental Management, School of Science, Information
Technology and Engineering, University of Ballarat, PO Box 663, Ballarat,

Centre for Environmental Management, School of Science, Information
Technology and Engineering, University of Ballarat, PO Box 663, Ballarat, Victoria, Australia
}

ineffectual in accurately determining ecological trajectories (Halle and Fattorini 2004). In this respect, the persistence of potentially ambiguous definitions of restoration activities and success (by practitioners), conflicting ecological theories (by academics) and a lack of clear guidelines (by regulators) has created some uncertainty about which parameters are the most important for determining the nature of ecological resilience and long-term stability. Whilst it is well documented that monitoring multiple variables is most valuable in determining restoration success (Ruiz-Jaen and Aide 2005a,b; Cristescu et al. 2013), resource limitations make it essential to identify a concise 
suite of attributes that can be confidently used as measures to rapidly demonstrate restoration outcomes-especially for large-scale projects (Menz et al. 2013). Another more contentious concern (addressed as a central theme of this special issue by Perring, Audet and Lamb, eds.) involves determining whether targeting the reinstatement of predisturbance reference ecosystems is always the most appropriate outcome and whether the post-disturbance ecosystems are on-course toward 'natural' (historic), 'hybrid' or 'novel' outcomes (Hobbs et al. 2009). From a decidedly more pragmatic perspective, these factors underpin the challenges faced by practitioners, academics and regulators attempting to determine how similar field sampling sites should be prior to being deemed veritably or otherwise restored and, indeed, whether these sites are natural or novel.

So far, it appears that comparing sites with similar management histories across different points in time may more effectively establish whether sites are developing towards the restoration target or whether intervention is required to overcome specific ecological thresholds (Suding 2011). As is often the case for restoration sites in Australia (as elsewhere), which typically involve direct seeding practices as part of site preparation, vegetation composition and structure may change along natural succession pathways through the emergence and recruitment of seedlings (Clarke and Davison 2001). Populations may ultimately decline if recruitment rates are less than mortality rates (Clarke and Davison 2004), which makes this ratio a useful monitoring parameter among rehabilitated sites. The diversity of woody plant species-which have easily recognisable reproductive material and which all recruit seedlings-provides easily measured parameters that have the potential to allow the determination of early establishment success and long-term ecological development of restored ecosystems.

This project aimed to determine the effectiveness of monitoring such plant reproductive parameters in the Lurg Hills district, Victoria (Australia), as indicators of plant recruitment. Our study design compared the relative similarities between remnant, unrestored and different aged restoration sites with a particular investigative focus on (i) species composition of woody seedlings and (ii) composition of woody functional groups with buds, flowers or fruits present. Besides the obvious intention of determining restoration success of the sites themselves, this study also seeks to determine the utility of using plant recruitment and functionality traits as bioindicators for similar monitoring protocols.

\section{Bioregional description}

The Lurg Hills district $\left(36^{\circ} 35^{\prime} \mathrm{S}, 146^{\circ} 07^{\prime} \mathrm{E}\right)$ is located approximately $220 \mathrm{~km}$ north-east of Melbourne, Victoria, Australia (Figure 1). The region forms a connection between remnants of native vegetation occurring in the foothills of the Great Dividing Range and the Warby Ranges State Park (Thomas 2009). This landscape-which was largely cleared for agricultural purposes-receives approximately $668 \mathrm{~mm}$ mean annual rainfall, with mean temperatures ranging between 3.2 and $12.8^{\circ} \mathrm{C}$ in July and 14.9 and $31.0^{\circ} \mathrm{C}$ in January (Bureau of Meteorology 2011). During the given restoration study time frame (from 1996 to 2009), annual rainfall varied substantially (1996-2010), ranging from $243 \mathrm{~mm}$ in 2006 to $833 \mathrm{~mm}$ in 1996 at an average of $601 \mathrm{~mm}$ annually. Rainfall in the year the survey commenced was well above average at $946 \mathrm{~mm}$ following 4 notable years of below average rainfall.

The Regent Honeyeater Project (Thomas 2009) commenced ecological restoration in the Lurg district in 1994, with an aim to restore habitats for the critically endangered Regent Honeyeater Anthochaera phrygia and a range of other threatened and declining species. Since 1996, restoration activities have occurred at over 490 sites, with 70 direct seeding sites and an additional 371 fenced sites (to restrict livestock grazing), to protect over 1,378 ha of habitat (Thomas 2012). Restoration sites generally differed in their condition prior to treatment, but all were previously grazed and/or cropped. Targets for restoration were sites that (i) adjoined remnant vegetation, (ii) incorporated isolated paddock trees and (iii) created connections between vegetated areas by enhancing or widening roadside vegetation and creek lines (Thomas 2009). Tubestock planting was used for the majority of restoration, with direct local provenance seeding also used increasingly over the years. Sites were generally prepared by ripping dry soils, followed by herbicide application after germination of winter weeds, and were ultimately fencedin to exclude livestock (Thomas 2009). Between 35 and 40 tree, shrub and groundcover species were planted manually after scalping the upper surface to remove the weed seed, and carton guards were used to protect plants. Follow-up weed control efforts were not consistent across all restoration sites, and replacement plantings were undertaken in following years at sites with high losses, which were due to damage from wildlife. No artificial irrigation methods were used with the exception of sites planted very late in the season.

\section{Methods}

\section{Sampling design}

A total of 438 sites were restored between 1996 and 2010 (Thomas 2012). Factorial blocking design and elimination criteria were used to account for natural variation and other differences among restoration sites. Elimination criteria included size, fencing and restoration method. The sites were between 1 and 7 ha in size, continuously fenced from stock since restoration, and planted with tubestock only. Two blocking factors of interest were used to further minimise confounding 


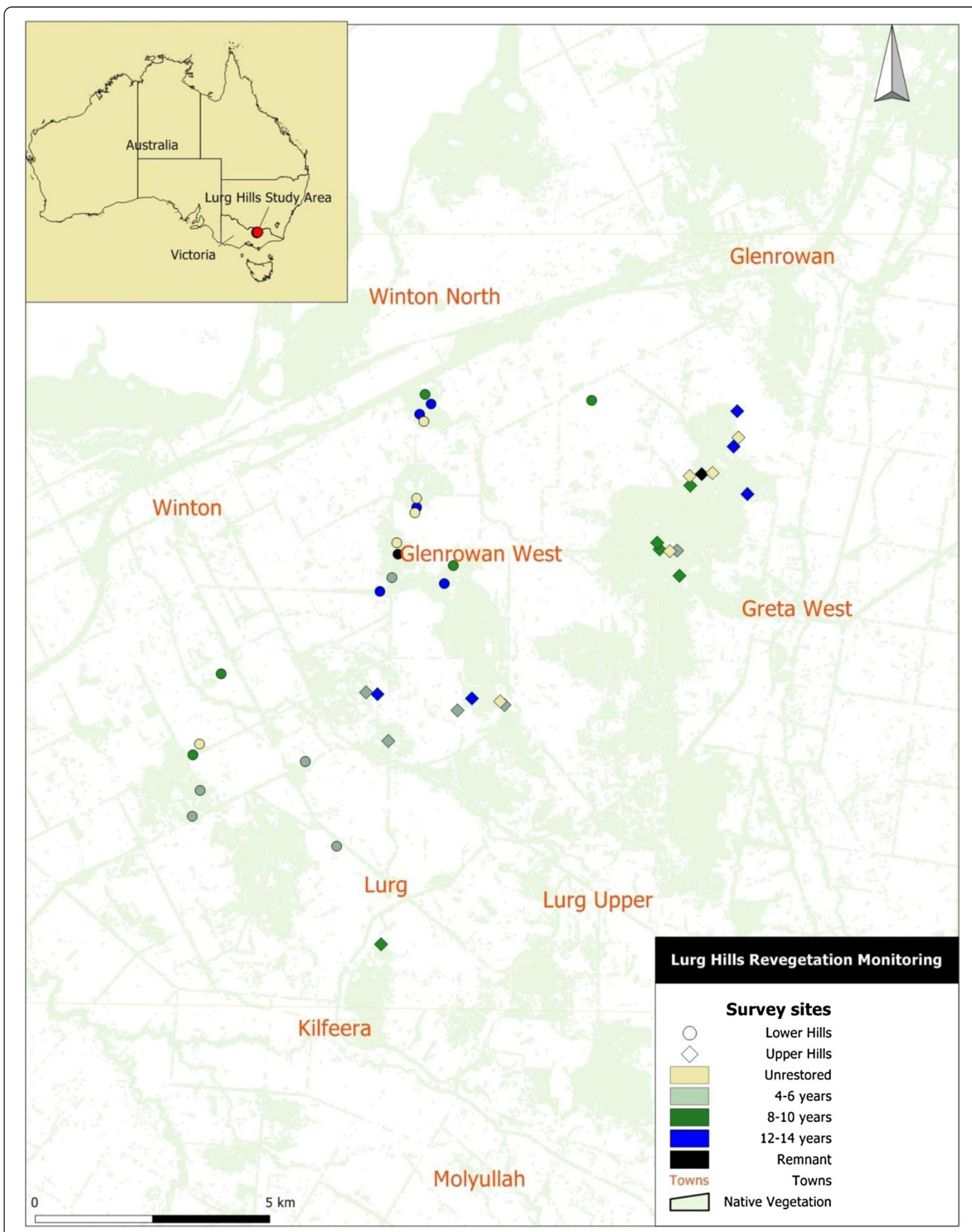

Figure 1 Location of study site and restoration sites. 
variables, these being (i) restoration age and (ii) landform and vegetation community characteristics.

\section{Restoration age}

Sites were categorised according to the time since the restoration planting. Space-for-time substitution was used to capture the different number of years since restoration. Three periods were selected to reflect significantly different stages of development and growth, with sites less than 4 years since planting being excluded from selection, as some species may not have reached reproductive maturity. This was in line with Wilkins et al. (2003), who found only slight differences in floristic composition between unrestored and restored sites up to 9 years old. The restoration ages selected for evaluation were: 4-6 years old (planted in 2004-2006); $8-10$ years (2000-2002); and $12-14$ years (1996-1998).

\section{Landform and vegetation}

Lurg landform categories were created using distinguishing landform characteristics detailed in Speight (2009), in combination with descriptions in the Revegetation Guide for the Goulburn Broken Catchment (Earl et al. 2001). Elevations were measured against the lowest location in the district, which was the Winton Wetlands, at approximately $170 \mathrm{~m}$ above sea level. Sites were allocated to landform categories based on mapped contour lines, and those sites on the boundary between two categories were allocated subjectively to the appropriate category using this mapping as a guide.

Landform categories were compared against modelled ecological vegetation classes [ecological vegetation classes (EVCs) are vegetation community classifications based on a combination of floristic, structure (life forms) and ecological characteristics and landscape position (Department of Sustainability and Environment 2013)] in the study area. Two broad landform categories (upper hills, lower hills) were selected from which the study sites were chosen, with the remaining categories (granitic hills, plains and wetlands) excluded due to inadequate replicates across the chosen age groups. The upper hills incorporated the dry steeper slopes of eucalypt-dominated forest with a shrubby or grassy understorey (Figure 2). The lower hills were gentler slopes of eucalypt woodland, with a sparse understorey of shrubs, herbs and grasses and with leaf litter dominating the groundlayer (Figure 3).

\section{Site selection}

A total of 42 sites were sampled equally across the two landforms (Table 1), each of which contained 15 restored sites (comprising 5 in each of three age categories), five unrestored sites and one remnant site, with the restored sites being randomly selected to ensure site selection was objective and unbiased. The unrestored (pre-restoration) sites facilitated comparison between restored and unrestored sites, allowing a determination of the effects of restoration. Due to the small sample size and the large number of potential unrestored sites under a range of management regimes, these sites were purposefully selected, based on management regimes, to represent the range of conditions. In addition, intact reference sites were difficult to locate due to the history of clearing in the district, thus only one remnant site was sampled in each landform category.

\section{Data collection and analysis}

Data were collected from 337 quadrats across 42 sites in the summer of 2010-2011. The number of quadrats

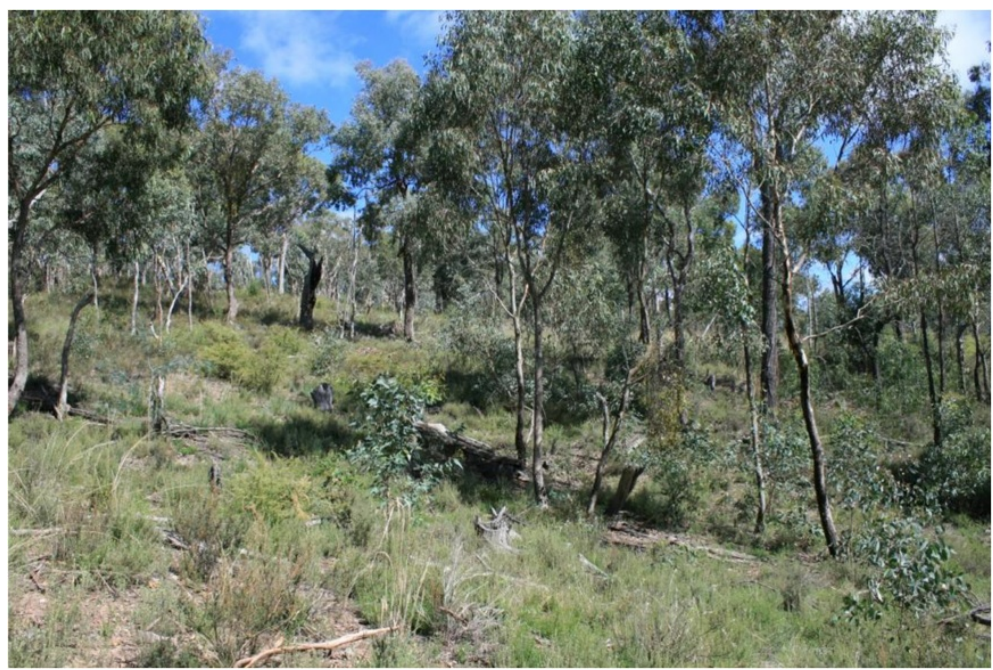

Figure 2 Vegetation community of the upper hills: eucalypt forest with a shrubby or grassy understorey (EVC shrubby dry forest / grassy dry forest). 


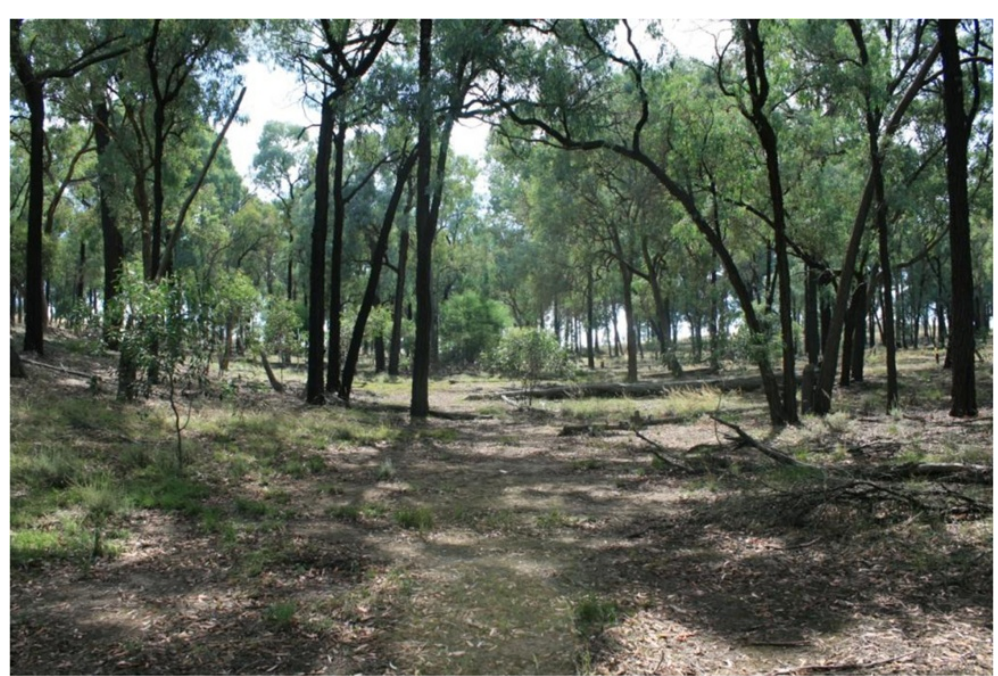

Figure 3 Vegetation community of the lower hills: eucalypt woodland with a sparse understorey of shrubs, herbs and grasses and with leaf litter dominating the groundlayer (EVC box ironbark forest).

sampled at a site differed to ensure that the area surveyed was proportional to the size of each site. Dimensions of the $120 \mathrm{~m}^{2}$ quadrats differed based on the shape of the restoration site. A systematic search was conducted to locate planted and regenerating individuals in each quadrat. The species type and the height and diameter at base were recorded for each plant. Diameters were measured using Vernier calipers or a diameter measuring tape where the diameter exceeded $150 \mathrm{~mm}$. Heights were measured using a $2 \mathrm{~m}$ ruler or a Silva clinometer for taller plants. The presence of reproductive material (buds, flowers, fruits) was recorded for each plant. Remnant trees were measured using the same method if they were present within a sampled quadrat. Recruitment was considered episodic if there were large numbers of individuals of the same age class and species within a quadrat (for example, if there were river red-gum seedlings in a drainage line). Where regeneration was clearly arising from suckers, this was noted due to the different reproductive method.

Multivariate analysis, using Primer $6^{\odot}$ (Primer-E, Ltd, Lutton, UK), was conducted to compare similarities between sites of different age classes using analysis of similarity (ANOSIM) and Bray-Curtis dissimilarity measures. Similarity percentage analysis (SIMPER) was then

Table 1 Number of sites sampled in each restoration age class and landform combination

\begin{tabular}{lcc}
\hline Restoration age class & Lower hills & Upper hills \\
\hline Unrestored (pasture) & 5 & 5 \\
Restored (4-6 years old) & 5 & 5 \\
Restored (8-10 years old) & 5 & 5 \\
Restored (12-14 years old) & 5 & 5 \\
Remnant vegetation & 1 & 1 \\
\hline
\end{tabular}

conducted to investigate which variables contributed most to these differences. Within-group similarities were not calculated for the remnant due to the absence of replicates. Multidimensional scaling (MDS) plots, using Bray-Curtis dissimilarity measures, were used to create an ordination of the site data. Data at each site were pooled and the mean number of seedlings per quadrat determined. Functional groups were defined based on lifeforms in the Habitat Hectares approach (Department of Sustainability and Environment 2004). Seedlings were allocated to groups based on description and height.

\section{Results}

\section{Seedling species composition}

Seedlings of various species were recorded in $88 \%$ of sites. There was evidence of recruitment at most of the restored and remnant sites in the upper hills, the exceptions being two restored sites (4-6 and 12-14 years old). In contrast, there was virtually no evidence of recruitment at unrestored sites in the lower hills, where only one seedling was recorded. Thirty-seven species of trees and shrubs (from eight families) were regenerating across the surveyed sites, 22 of which occurred in both landform categories. Eucalypts were mainly found regenerating near large old remnant trees. A rare species in the district, the western golden-tip Goodia medicaginea, was recruited in small numbers at both landforms. The total number of species recruiting differed by age class, ranging from 0 to 18 in the lower hills, and 0 to 20 in the upper hills. No woody weeds were recorded in any sites.

\section{Lower hills}

Seedling species composition differed significantly among age classes in the lower hills (global $\mathrm{R}=0.378, p=0.001$ ). 
ANOSIM pairwise comparisons indicated the age classes that were most different in seedling species composition were unrestored and restored (12-14 years) (Table 2). Other age classes that differed were unrestored and restored (8-10 years); restored (4-6 years) and restored (810 years); and restored (8-10 years) and restored (12-14 years). The MDS ordination (Figure 4) showed older restored sites were closer in seedling composition to the remnant than the younger age classes were. Variation between sites of the same age decreased with time since restoration, with most variation occurring between restored (4-6 years) sites. This is supported by the SIMPER analysis, which showed within-group similarities increased with restoration age from $8.21 \%$ similarity in restored (46 years), to $19.23 \%$ in restored (12-14 years). These similarities were due to a few species: Acacia dealbata (51.28\%) in restored (4-6 years), Dodonaea viscosa ssp. angustissima (76.23\%) in restored (8-10 years) and Acacia pycnantha $(76.61 \%)$ in restored (12-14 years). Dissimilarity between age classes were due to a range of species (Additional file 1: Appendix 1). Species which contributed most to within-group similarity were also largely responsible for between-group dissimilarity. Sites became more like the remnant with increased time since restoration.

\section{Upper hills}

No significant differences were found in the species composition of seedlings between different age classes in the upper hills (ANOSIM global R statistic 0.114; $p=0.068$ ).

\section{Reproductive outputs \\ Buds and flowers}

Lower hills The composition of functional groups with buds or flowers was significantly different among age classes $(\mathrm{R}=0.254, p=0.003)$. ANOSIM pairwise comparisons revealed the differences occurred between the unrestored and both restored (8-10 years) and restored (12-14 years) age classes (Table 3). SIMPER analysis (Additional file 2: Appendix 2) showed that the main sources of variability between unrestored sites and the restored (8-10 years) and restored (12-14 years) age classes were immature trees and medium shrubs, and immature trees respectively. Unrestored sites generally decreased in dissimilarity to the unrestored age class with time since restoration. Dissimilarities between the remnant and all other groups were alike, which was mainly due to the higher number of canopy trees with buds or flowers in the remnant. Unrestored and the youngest restored sites had low within-group similarities (20.37 and $15.68 \%$ respectively); this increased with restoration age (46.65 and $51.58 \%$ similarity for $8-10$ years and 12-14 years respectively). Younger sites had a more diverse mix of small and medium shrubs, immature trees and trees with flowers.

Upper hills The composition of functional groups with buds or flowers was significantly different among age classes $(\mathrm{R}=0.543 ; p=0.001)$. ANOSIM pairwise comparisons (Table 4) indicated the differences occurred between unrestored and all restored age classes, and between restored (4-6 years) and restored (12-14 years). SIMPER analysis (Additional file 3: Appendix 3) showed that differences between unrestored and restored sites were mostly due to medium shrubs in the two younger restored age classes, and immature trees in the two older restored age classes. Medium shrubs at restored (4-6 years) sites and immature trees at restored (12-14 years) sites were largely responsible for differences between the two age classes. Dissimilarity decreased with time since restoration for all age classes. Unrestored sites in the upper hills contained no woody plants with buds or flowers. Restored age classes increased slightly in withingroup similarity with age (52.99, 55.62 and 59.42\%), mainly due to medium shrubs in the two younger restored groups and immature trees in the oldest restored age class.

\section{Fruits}

Lower hills ANOSIM analysis demonstrated significant differences in the average number of woody plants with fruits in each functional group among age classes $(\mathrm{R}=0.318 ; p=0.001)$. These differences occurred between unrestored and all restored age classes (Table 5), and between restored (4-6 years) and restored (12-14 years).

Table 2 Species composition of seedlings in lower hills

\begin{tabular}{|c|c|c|c|c|c|c|c|c|}
\hline \multirow[t]{2}{*}{ Age class } & \multicolumn{2}{|c|}{ Unrestored } & \multicolumn{2}{|c|}{ Restored (4-6) } & \multicolumn{2}{|c|}{ Restored (8-10) } & \multicolumn{2}{|c|}{ Restored (12-14) } \\
\hline & R statistic & $p$ value & R statistic & $p$ value & R statistic & $\overline{p \text { value }}$ & R statistic & $p$ value \\
\hline Restored (4-6) & 0.063 & 0.183 & & & & & & \\
\hline Restored (8-10) & 0.571 & 0.008 & 0.364 & 0.008 & & & & \\
\hline Restored (12-14) & 0.697 & 0.008 & 0.210 & 0.087 & 0.512 & 0.008 & & \\
\hline Remnant & 0.000 & 1.000 & 0.040 & 0.333 & 0.240 & 0.500 & 0.120 & 0.667 \\
\hline
\end{tabular}

Species composition of seedlings in different aged sites in the lower hills (ANOSIM pairwise comparisons showing R statistic and significance level, with significant $p$-values in bold. Global $\mathrm{R}=0.378, p=0.001$ ). 


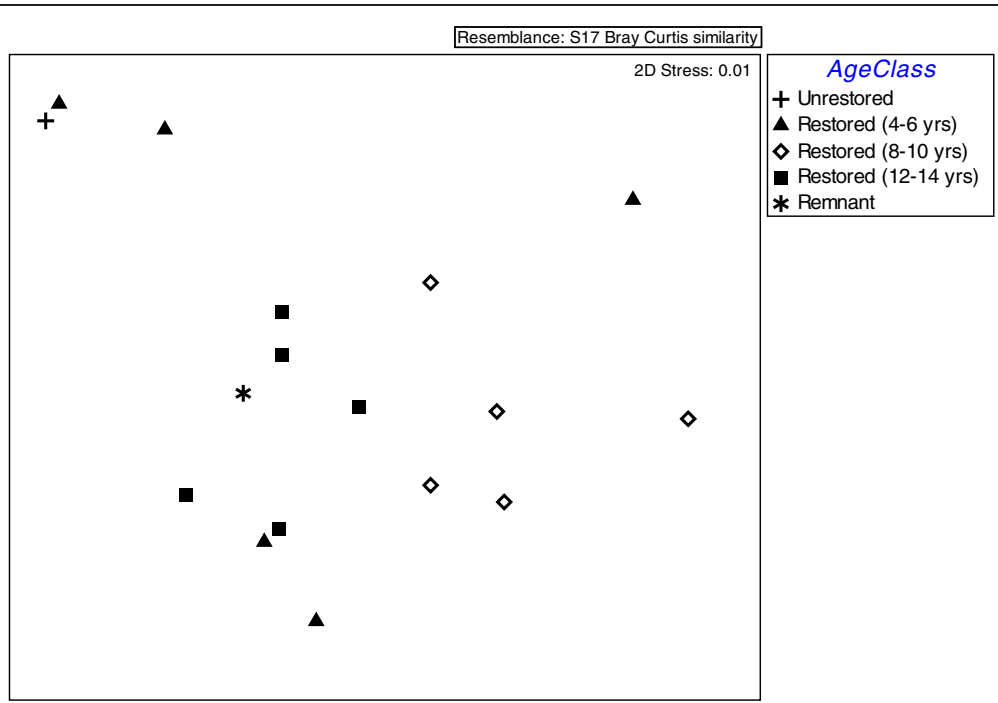

Figure 4 Species composition of seedlings in lower hills. MDS ordination of species composition of seedlings in different age classes in lower hills, with subset of data enlarged (four unrestored sites excluded from frame as clearly separated from remaining cluster).

Unrestored sites differed from restored sites mainly due to medium shrubs with fruits in restored (4-6 years) sites, and both medium shrubs and immature trees in the two older restored age classes (Additional file 4: Appendix 4). Differences between restored (4-6 years) and restored (12-14 years) age classes were mainly due to the abundance of immature trees and medium shrubs with fruits. The unrestored age class was most similar to the remnant due to the presence of canopy trees and a lack of shrubs with fruits in both age classes. Restored age classes were most similar to sites closest in age.

Similarities within age classes differed: 20.37\% (unrestored), 27.43\% (restored 4-6 years), 51.72\% (restored $8-10$ years) and $48.48 \%$ (restored $12-14$ years). Canopy trees were the main source of similarity in the unrestored age class, while medium shrubs and immature trees were the main source in the restored classes.

Upper hills Functional group composition with fruits differed significantly among age classes $(\mathrm{R}=0.568, p=0.001)$. All age classes were significantly different from each other except for the remnant (Table 6). Differences were mostly due to the abundance of medium shrubs with fruits (all restored age classes), and immature trees and trees at older restored sites (Additional file 5: Appendix 5). Dissimilarities between unrestored and other age classes decreased with age, due to the minor presence of remnant canopy trees (with fruits) in the unrestored age class. Remnants had more in common with older restored sites (8-10 years and 12-14 years). Restored age classes were more similar to restored sites closest in age. Restored (4-6 years) sites were most similar $(74.42 \%)$ to each other due to the presence of medium shrubs with fruits. Similarity was lower for the older restored age classes: restored (8-10 years) $(59.17 \%)$, restored (12-14 years) (55.05\%); however, the number of functional groups with fruits increased to include immature trees, plus trees in the oldest restored age class.

\section{Discussion}

Our study addresses rather typical restoration works in Australia (i.e., returning natural/native ecosystems following agricultural development), and some of the difficulties faced when attempting to define ecosystem development

Table 3 Composition of functional groups with buds or flowers in lower hills

\begin{tabular}{|c|c|c|c|c|c|c|c|c|}
\hline \multirow[t]{2}{*}{ Age class } & \multicolumn{2}{|c|}{ Unrestored } & \multicolumn{2}{|c|}{ Restored (4-6) } & \multicolumn{2}{|c|}{ Restored (8-10) } & \multicolumn{2}{|c|}{ Restored (12-14) } \\
\hline & R statistic & $p$ value & R statistic & $p$ value & R statistic & $p$ value & R statistic & $p$ value \\
\hline Restored (4-6) & 0.233 & 0.095 & & & & & & \\
\hline Restored (8-10) & 0.467 & 0.008 & 0.040 & 0.317 & & & & \\
\hline Restored (12-14) & 0.516 & 0.008 & 0.180 & 0.103 & 0.006 & 0.413 & & \\
\hline Remnant & -0.111 & 0.500 & -0.180 & 0.667 & 0.680 & 0.167 & 0.760 & 0.167 \\
\hline
\end{tabular}


Table 4 Composition of functional groups with buds or flowers in upper hills

\begin{tabular}{|c|c|c|c|c|c|c|c|c|}
\hline \multirow[t]{2}{*}{ Age class } & \multicolumn{2}{|c|}{ Unrestored } & \multicolumn{2}{|c|}{ Restored (4-6) } & \multicolumn{2}{|c|}{ Restored (8-10) } & \multicolumn{2}{|c|}{ Restored (12-14) } \\
\hline & R statistic & $p$ value & R statistic & $p$ value & R statistic & $p$ value & R statistic & $p$ value \\
\hline Restored (4-6) & 0.714 & 0.008 & & & & & & \\
\hline Restored (8-10) & 0.703 & 0.008 & 0.248 & 0.087 & & & & \\
\hline Restored (12-14) & 0.703 & 0.008 & 0.658 & 0.008 & 0.228 & 0.056 & & \\
\hline Remnant & -0.200 & 1.000 & 0.840 & 0.167 & 0.200 & 0.333 & 0.440 & 0.167 \\
\hline
\end{tabular}

Composition of functional groups with buds or flowers in different aged sites in the upper hills (ANOSIM pairwise comparisons showing R statistic and significance level, with significant $p$-values in bold. Global $\mathrm{R}=0.543, p=0.001$ ).

toward a given restoration target. In this regard, restoration plantings in the Lurg Hills generally developed in different ways across the two landforms studied (i.e., upper and lower hills). All sites were found in a hybrid state sharing some components with the remnant (historical) ecosystems, but also some novel proportional combinations of species assembly. Despite differences between groups, trends towards the restoration target were evident for species composition of seedlings only in the lower hills, and for bud/flower and fruit production only in the upper hills. For example, after 8 years, restored sites in the lower hills had a seedling composition that was very different to both unrestored and younger restored sites. Sites also became more similar to the remnant with time, particularly 12 years after restoration.

A range of development scenarios have been identified where sites may converge, diverge or deviate from the restoration target (Suding 2011). The majority of sites in the lower hills converged towards the target and also increased in similarity to sites of the same age class with time. This supports the idea that, as a community ages, the number of potential development trajectories may decrease due to plant competitive ability (Nuttle et al. 2004). However, a range of factors may have influenced these similarities within age classes. As Hobbs and Norton (2004) point out, the sites' starting conditions, order of species introductions and subsequent management will all interact to affect how a community will develop. Seed or microsite availability can also have a strong influence on the composition and structure of ecosystems through the failure of species to recruit (Clark et al. 2007). There were some instances where seedlings seemed to derive from adjoining remnant vegetation, as evidenced by patterns of seedling dispersal in relation to remnant trees, maturity of restored vegetation and restoration species lists. However, the majority of species recruiting were the same as those planted during restoration. While seeds were not tested for viability, it is likely much of the regeneration resulted from mature planted individuals (e.g., fruits were present on medium shrubs after only 4 years). Many studies show that recruitment of trees and shrubs is often affected to a greater extent by the availability of microsites, areas with suitable conditions for germination and growth (Clarke and Davison 2001; Clark et al. 2007; Gómez-Aparicio 2008). However, as the extent of potential recruitment is ultimately determined by the availability of viable seed (Clarke and Davison 2001), the production of adequate seed in restored ecosystems is clearly essential for achieving a target community. Introducing seed of additional species may help reduce any seed limitations (Hobbs and Norton 2004; Young et al. 2005; Clark et al. 2007) which may be caused by decreased pollination and dispersal opportunities (Bennett et al. 2009).

The lack of recruitment at two restored sites (4-6 years and 12-14 years) in the lower hills suggests divergence, which occurs when sites that have undergone similar restoration develop along different trajectories (Suding 2011). Structurally, these sites differ from other sites of the same age, which have a range of species recruiting. It would be worth investigating the barriers that are preventing recruitment, such as herbivory, microsite variations or seed availability. Some species present in reference ecosystems may not re-establish under current conditions unless regeneration niches are provided (Zedler et al. 2012), yet

Table 5 Composition of functional groups with fruits in lower hills

\begin{tabular}{|c|c|c|c|c|c|c|c|c|}
\hline \multirow[t]{2}{*}{ Age class } & \multicolumn{2}{|c|}{ Unrestored } & \multicolumn{2}{|c|}{ Restored (4-6) } & \multicolumn{2}{|c|}{ Restored (8-10) } & \multicolumn{2}{|c|}{ Restored (12-14) } \\
\hline & R statistic & $p$ value & R statistic & $p$ value & R statistic & $p$ value & R statistic & $p$ value \\
\hline Restored (4-6) & 0.428 & 0.024 & & & & & & \\
\hline Restored (8-10) & 0.520 & 0.008 & 0.068 & 0.246 & & & & \\
\hline Restored (12-14) & 0.474 & 0.008 & 0.218 & 0.032 & -0.052 & 0.620 & & \\
\hline Remnant & -0.111 & 0.500 & 0.520 & 0.330 & 1.000 & 0.167 & 1.000 & 0.167 \\
\hline
\end{tabular}

Composition of functional groups with fruits in different aged sites in the lower hills (ANOSIM pairwise comparisons showing R statistic and significance level, with significant $p$-values in bold. Global $\mathrm{R}=0.318, p=0.001$ ). 
Table 6 Composition of functional groups with fruits in upper hills

\begin{tabular}{|c|c|c|c|c|c|c|c|c|}
\hline \multirow[t]{2}{*}{ Age class } & \multicolumn{2}{|c|}{ Unrestored } & \multicolumn{2}{|c|}{ Restored (4-6) } & \multicolumn{2}{|c|}{ Restored (8-10) } & \multicolumn{2}{|c|}{ Restored (12-14) } \\
\hline & R statistic & $p$ value & R statistic & $p$ value & R statistic & $p$ value & R statistic & $p$ value \\
\hline Restored (4-6) & 0.647 & 0.008 & & & & & & \\
\hline Restored (8-10) & 0.619 & 0.008 & 0.460 & 0.016 & & & & \\
\hline Restored (12-14) & 0.619 & 0.008 & 0.856 & 0.008 & 0.260 & 0.040 & & \\
\hline Remnant & -0.200 & 0.667 & 1.000 & 0.167 & 0.680 & 0.167 & 0.640 & 0.167 \\
\hline
\end{tabular}

Composition of functional groups with fruits in different aged sites in the upper hills (ANOSIM pairwise comparisons showing R statistic and significance level, with significant $p$-values in bold. Global $\mathrm{R}=0.568, p=0.001$ ).

recruitment of seedlings 8 years after restoration indicates niches have been provided for many indigenous speciesincluding rare species such as Goodia medicaginea, which was found recruiting in small numbers in both landforms. In addition, no woody weeds were recorded at either landform. Therefore, seedlings and the structure of the tree and shrub layers were composed solely of remnants or planted indigenous species sourced from local provenance.

Zedler et al. (2012) argue that sites that need constant redirection towards their target ecosystem might be more sustainable if retained as novel ecosystems, thereby acknowledging the barriers preventing veritable restoration. With the exception of the two sites lacking seedlings, if diverse recruitment of indigenous species continues to occur, hybrid ecosystems could be retained in preference to novel ones, and have the potential to become more similar to a natural or historical ecosystem with time. If biota cannot regenerate, development into a novel ecosystem will probably occur (Hobbs et al. 2009). The insignificant difference in species composition of seedlings in the upper hills may be due to further factors (not investigated in the present context) involving more subtle or site-specific management practices, e.g., due to different historical land-usage intensities. Alternatively, potentially large variability in abiotic factors across the steeper upper hills (such as aspect, slope, moisture availability and proximity to larger patches of remnant vegetation) may be an influence.

Restored sites had buds, flowers and fruits after 4 years in the upper hills, with sites becoming more similar to the remnant as rapidly as 8 years after restoration. The absence of a clear trend towards a restoration target for bud/flower and fruit production in the lower hills may be due to the presence of canopy trees in both the unrestored and remnant sites, and the diverse range of functional groups with buds/flowers or fruits in the restored sites, which were fewer in the remnant. This resulted in greater similarity between the remnant and unrestored sites. While the more fertile, gentler slopes of the lower hills may have influenced the production of buds/flowers and fruits on a diverse range of functional groups, the different stages of ecological development of the restored sites and the remnant may have been a factor. As only one remnant was surveyed in each landform, this was a limitation of the study. The different vegetation structure in the late stage of ecological development of the remnant is also likely to have an impact when assessing restoration success; as Suding and Hobbs (2009) point out, each reference site may reflect only one of the many stages of development, any of which would form the model for restoration.

\section{Has restoration in the Lurg Hills been successful?}

Despite much debate surrounding the use of remnant ecosystems as restoration targets (Hobbs and Harris 2001; Harris et al. 2006; Hobbs et al. 2009; Palmer et al. 2006; Choi 2007; Comín 2010), these selected reference systems are still commonly used to determine site-specific restoration success. In this regard, seedling recruitment and reproductive parameters provide limited insight into whether sites are developing towards a restoration target. The establishment of self-sustaining ecosystems is an ecological attribute the Society for Ecological Restoration International Science and Policy Working Group (2004) proposes using to evaluate restoration success. Given seedlings recruited in most sites in the Lurg Hills, most of the restoration could be deemed successful at this point in time. The presence of seedlings signifies a life cycle has successfully been completed, as transplanted individuals have flowered, set fruit, dispersed seed and recruited new seedlings (Menges 2008). In addition, microsite conditions have clearly been conducive to germination and growth. While it may be preferable from a management perspective for sites to converge together along a predictable pathway towards a restoration target, Suding (2011) argues that resilience may be increased if there is variability at a landscape scale. Resilience is vital for an ecosystem to adapt and recover from disturbances, while still maintaining ecological function and health (Folke et al. 2004; Walker and Salt 2006; Clewell and Aronson 2007). Diversity is thought to influence ecosystem resilience (Grant 2009; Allen et al. 2010); therefore, variability among sites of the same age may in fact be beneficial in the longer term, increasing resilience through differences in diversity as seedlings mature and alter vegetation structure and composition. This is particularly relevant under uncertain future conditions including climate change, as increased human demand places 
further pressure on ecosystems, which may not remain stable (Folke et al. 2004).

\section{Conclusions}

The majority of ecological restoration sites in the Lurg Hills have successfully recruited woody seedlings from a range of species, as early as 4 years after restoration. Most sites are in a hybrid state, developing towards the restoration target and becoming more similar to the remnant site and more distant from unrestored sites with age. However, this differed between landforms. The diversity of functional groups producing buds, flowers or fruits is also promising for the future of these restoration sites. Intervention may be useful at some sites where no recruitment occurred, by introducing additional seed or creating further opportunities for seed germination and establishment through targeted disturbance. Provided diversity is maintained and there are dispersal and recruitment opportunities through landscape connectivity, the deviation or divergence of some sites from the restoration target may not be an issue as resilience may potentially be increased by variability across the landscape. Plant recruitment was effective in detecting development trends towards a restoration target in this study and therefore is considered a useful measure that contributes to detecting ecological restoration success.

\section{Additional files}

Additional file 1: Appendix 1. Average Bray-Curtis dissimilarities (in bold) between all pairs of age classes (lower hills), with species contributing most dissimilarity between groups (top cumulative 50\%).

Additional file 2: Appendix 2. Average Bray-Curtis dissimilarities (in bold) between all pairs of age classes (lower hills), with functional groups (life forms) with buds/flowers contributing most dissimilarity between groups (top cumulative 50\%)

Additional file 3: Appendix 3. Average Bray-Curtis dissimilarities (in bold) between all pairs of age classes (upper hills), with functional groups with buds/flowers contributing most dissimilarity between groups (top cumulative 50\%).

Additional file 4: Appendix 4. Average Bray-Curtis dissimilarities (in bold) between all pairs of age classes (lower hills), with functional groups with fruits contributing most dissimilarity between groups (top cumulative 50\%).

Additional file 5: Appendix 5. Average Bray-Curtis dissimilarities (in bold) between all pairs of age classes (upper hills), with functional group with fruits contributing most dissimilarity between groups (top cumulative 50\%).

\section{Competing interests}

KM was an employee of the Regent Honeyeater Project between June 2009 and January 2010, and a volunteer for several years. The other authors declare that they have no competing interests with regard to any of the reported findings.

\section{Authors' contributions}

KM gathered, analysed and interpreted the data and primarily drafted the manuscript. SF and GP provided initial research ideas, design and refined methodology. SF and GP provided editorial commentary. All authors read and approved the final manuscript.

\section{Acknowledgements}

Authors would like to thank Ray Thomas of the Regent Honeyeater Project for his willingness to provide access to project file notes and maps. We thank Dale Robinson, John Miller, Lucinda Monie, Kim Magnay, Tim D'Ombrain, Jacqui Monie and Belinda Taylor for their help in the field. We thank landholders in the Lurg district for allowing us to work on their properties. We also thank Tony Wilson and Tricia Wevill for statistical techniques. We thank Drs. Patrick Audet (The University of Queensland, Queensland) and Michael Perring (University of Western Australia, Perth) for providing constructive feedback on the earlier versions of our manuscript. The financial support was provided by The Regional Futures Grant, University of Ballarat.

Received: 7 May 2013 Accepted: 4 September 2013

Published: 17 September 2013

\section{References}

Allen CR, Gunderson LH, Holling CS (2010) Commentary on part one articles. In: Allen CR, Holling C, Gunderson LH (eds) Foundations of ecological resilience. Island Press, Washington DC

Bennett AF, Haslem A, Cheal DC, Clarke MF, Jones RN, Koehn JD, Lake PS, Lumsden LF, Lunt ID, Mackey BG, Mac Nally R, Menkhorst PW, New TR, Newell GR, O'Hara T, Quinn GP, Radford JQ, Robinson D, Watson JEM, Yen AL (2009) Ecological processes: a key element in strategies for nature conservation. Ecol Manage Restor 10(3):192-199

Bureau of Meteorology (2011) Climate statistics for Australian locations: monthly climate statistics., http://www.bom.gov.au/climate/averages/tables/ cW_082002.shtml. Accessed 15 Dec 2011

Choi YD (2007) Restoration ecology to the future: a call for a new paradigm. Restor Ecol 15(2):351-353

Clark CJ, Poulsen JR, Levey DJ, Osenberg CW (2007) Are plant populations seed limited? A critique and meta-analysis of seed addition experiments. Am Nat 170(1):128-150

Clarke PJ, Davison EA (2001) Experiments on the mechanism of tree and shrub establishment in temperate grassy woodlands: seedling emergence. Aust Ecol 26:400-412

Clarke PJ, Davison EA (2004) Emergence and survival of herbaceous seedlings in temperate grassy woodlands: recruitment limitations and regeneration niche. Aust Ecol 29:320-331

Clewell AF, Aronson J (2007) Ecological restoration: principles, values, and structure of an emerging profession. Island Press, Washington DC

Comín FA (2010) The challenges of humanity in the twenty-first century and the role of ecological restoration. In: Comín F (ed) Ecological restoration: a global challenge. Cambridge University Press, New York

Cristescu RH, Rhodes J, Frére C, Banks PB (2013) Is restoring flora the same as restoring fauna? Lessons learned from koalas and mining rehabilitation. J App Ecol 50:423-431

Department of Sustainability and Environment (2004) Native vegetation: sustaining a living landscape. Vegetation quality assessment manual: guidelines for applying the habitat hectares scoring method. Version 1.3. Department of Sustainability and Environment, Melbourne, Australia

Department of Sustainability and Environment (2013) Native vegetation - information., http://www.dse.vic.gov.au/land-management/ land/native-vegetation-home/native-vegetation-information. Accessed 23 Apr 2013

Earl G, Stelling F, Titcumb M, Berwick S (eds) (2001) Revegetation guide for the Goulburn broken catchment. Dept. of Natural Resources \& Environment, East Melbourne

Folke C, Carpenter S, Walker BS, Elmqvist T, Gunderson L, Holling C (2004) Regime shifts, resilience, and biodiversity in ecosystem management. Annu Rev Ecol Evol Syst 35:557-581

Gómez-Aparicio L (2008) Spatial patterns of recruitment in Mediterranean plant species: linking the fate of seeds, seedlings and saplings in heterogeneous landscapes at different scales. J Ecol 96:1128-1140

Grant C (2009) State-and-transition models for mining restoration in Australia. In: Hobbs R, Suding K (eds) New models for ecosystem dynamics and restoration. Island Press, Washington DC, pp 280-294

Halle S, Fattorini M (2004) Advances in restoration ecology: insights from aquatic and terrestrial ecosystems. In: Temperton V, Hobbs R, Nuttle T, Halle S (eds) 
Assembly rules and restoration ecology: bridging the gap between theory and practice. Island Press, Washington DC, pp 10-33

Harris JA, Hobbs RJ, Higgs E, Aronson J (2006) Ecological restoration and global climate change. Restor Ecol 14(2):170-176

Hobbs R, Harris J (2001) Restoration ecology: repairing the Earth's ecosystems in the new millenium. Restor Ecol 9(2):239-246

Hobbs RJ, Higgs E, Harris JA (2009) Novel ecosystems: implications for conservation and restoration. Trends Ecol Evol 24(11):599-605

Hobbs RJ, Norton DA (2004) Ecological filters, thresholds, and gradients in resistance to ecosystem reassembly. In: Temperton V, Hobbs R, Nuttle T, Halle $S$ (eds) Assembly rules and restoration ecology: bridging the gap between theory and practice. Island Press, Washington DC, pp 72-95

Lindenmayer DB, Likens GE (2010) Effective ecological monitoring. CSIRO, Collingwood, VIC

Lindenmayer DB, Likens GE, Anderson A, Bowman D, Bull CM, Burns E, Dickman CR, Hoffmann AA, Keith DA, Liddell MJ, Lowe AJ, Metcalfe DJ, Phinn SR, Russell-Smith J, Thurgate N, Wardle GM (2012) Value of long-term ecological studies. Aust Ecol 37:745-757

Menges ES (2008) Turner review no. 167. Restoration demography and genetics of plants: when is a translocation successful? Aust J Bot 56(3):187-196

Menz MHM, Dixon KW, Hobbs RJ (2013) Hurdles and opportunities for landscapescale restoration. Science 339:526-527

Nuttle T, Hobbs RJ, Temperton VM, Halle S (2004) Assembly rules and ecosystem restoration: where to from here? In: Temperton V, Hobbs R, Nuttle T, Halle S (eds) Assembly rules and restoration ecology. Island Press, Washington DC, pp 410-421

Palmer MA, Falk DA, Zedler JB (2006) Ecological theory and restoration ecology. Foundations of restoration ecology. Island Press, Washington DC, pp, In, pp 1-10

Ruiz-Jaen MC, Aide TM (2005a) Restoration success: how is it being measured? Restor Ecol 13(3):569-577

Ruiz-Jaen MC, Aide TM (2005b) Vegetation structure, species diversity, and ecosystem processes as measures of restoration success. For Ecol Manage 218(1-3):159-173

Society for Ecological Restoration International Science and Policy Working Group (2004) The SER international primer on ecological restoration. SER, Washington DC

Speight JG (2009) Landform. In: National Committee on Soil and Terrain (ed) Australian soil and land survey field handbook, 3rd edn. CSIRO Publishing, Melbourne

Suding KN (2011) Toward an era of restoration in ecology: successes, failures, and opportunities ahead. Annu Rev Ecol Evol Syst 42:465-487

Suding KN, Hobbs RJ (2009) Models of ecosystem dynamics as frameworks for restoration ecology. In: Hobbs R, Suding K (eds) New models for ecosystem dynamics and restoration. Island Press, Washington DC, pp 3-21

Thomas R (2009) Regent Honeyeater habitat restoration project Lurg Hills, Victoria. Ecol Manage Restor 10(2):84-97

Thomas R (2012) Overall achievements. Regent Honeyeater Newsl Summer, pp 2011-12

Walker B, Salt D (2006) Living in a complex world: an introduction to resilience thinking. In: Resilience thinking: sustaining ecosystems and people in a changing world. Island Press, Washington DC, pp 1-14

Wilkins S, Keith DA, Adam P (2003) Measuring success: evaluating the restoration of a grassy eucalypt woodland on the Cumberland Plain, Sydney, Australia. Restor Ecol 11(4):489-503

Young TP, Peterson DA, Clary JJ (2005) The ecology of restoration: historical links, emerging issues and unexplored realms. Ecol Lett 8:662-673

Zedler JB, Doherty JM, Miller NA (2012) Shifting restoration policy to address landscape change, novel ecosystems, and monitoring. Ecol Soc 17(4), 10.5751/ES-05197-170436

doi:10.1186/2192-1709-2-27

Cite this article as: Monie et al:: Recruitment and functionality traits as bioindicators of ecological restoration success in the Lurg Hills district, Victoria, Australia. Ecological Processes 2013 2:27.

\section{Submit your manuscript to a SpringerOpen ${ }^{\odot}$ journal and benefit from:}

- Convenient online submission

- Rigorous peer review

- Immediate publication on acceptance

- Open access: articles freely available online

- High visibility within the field

- Retaining the copyright to your article

Submit your next manuscript at $\gg$ springeropen.com 